\title{
Biochanin a Versus17beta Estradiol Effect in Rat Submandibular Salivary Gland; Natural Alternative or an Endocrine Disruptor! (Transmission Electron Microscope)
}

ISSN: 2637-7764

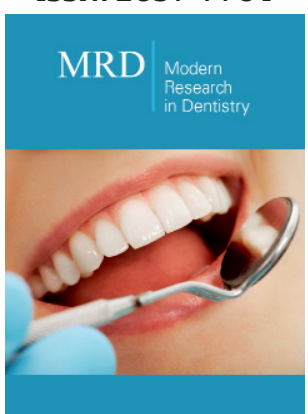

*Corresponding author: Amira M El Sherbini, Lecturer in Oral Biology Department, Faculty of dentistry, Mansoura University, Egypt

Submission: 眥 November 21, 2019

Published: 毕 December 17, 2019

Volume 4 - Issue 5

How to cite this article: Amira $\mathrm{M}$ El Sherbini, Mohammed Abdul Rahman M, Fatma M I. Biochanin a Versus17beta Estradiol Effect in Rat Submandibular Salivary Gland; Natural Alternative or an Endocrine Disruptor! (Transmission Electron Microscope). Mod Res Dent. 4(5). MRD.000596.2019.

DOI: 10.31031/MRD.2019.04.000596

Copyright@ Amira M El Sherbini, This article is distributed under the terms of the Creative Commons Attribution 4.0 International License, which permits unrestricted use and redistribution provided that the original author and source are credited.

\author{
Amira M El Sherbini ${ }^{1 *}$, Mohammed Abdul Rahman $\mathbf{M}^{2}$ and Fatma M Ibrahim ${ }^{3}$ \\ ${ }^{1}$ Lecturer in Oral Biology Department, Egypt \\ ${ }^{2}$ Associate professor in Oral Biology Department, Egypt \\ ${ }^{3}$ Professor in Oral Biology Department, Egypt
}

\begin{abstract}
s
The ultrastructure of Submandibular gland [SMG] following low dose of Biochanin a [BCA] and 17beta estradiol [E2] application was observed. The pups were allocated randomly into control, BCA, E2, Dimethyl sulphoxide [DMSO] and euthanized at the $6^{\text {th }}, 14^{\text {th }}, 30^{\text {th }}, 60^{\text {th }}$ postnatal days [PND]. The SMG acinar and ductal structure, in addition to telocytes, were altered with the compounds of concern.
\end{abstract}

Keywords: Biochanin A; 17beta estradiol; Endocrinal disruptor

Abbreviations: BCA: Biochanin A; E2: 17beta estradiol; DMSO: Dimethylsulphoxide; SMG: Submandibular Salivary Gland; ED: Endocrinal Disruptor; TE: Transmission Electron Microscope; PND: Postnatal Day; gp: Group; M: Mitochondria; N: Nuclei; L: Lumen; rER: Rough Endoplasmic Reticulum; SG: Secretory Granules

\section{Introduction}

Known for various biological activities, biochanin A [BCA] is a plant extract that can be found in red clover [1]. Biochanin A acts also as anti-proliferative, anti-inflammatory agent [2,3] and anti-tumorigenic effect through inhibition of several enzymatic activity and apoptosis induction [3-6]. BCA is known for its estrogenic activity because it can bind with both alpha $(E R \alpha)$ and beta (ER $\beta$ ) estrogen receptors [7]. The $17 \beta$ estradiol is the main sponsor to estrogen-dependent processes in peripheral tissues [8]. Likewise, it is the main determinant for the proliferation of breast cancer cells in vivo $[9,10]$. In an attempt to avoid the risks, the search for alternative therapy is justified [11]. Estrogen receptors [predominantly ER $\beta$ ] are expressed in submandibular gland more than the other major salivary glands. Thus, implicating a role of salivary gland in reproductive and peripheral organ development and/ or regeneration [12]. The rodent SMG exhibits extensive development of its parenchymal elements in postnatal periods [13]. Hereby the prepubertal development of rat SMG following low dose of Biochanin a [BCA] and 17beta estradiol [E2] exposure was observed. As far as we know this is the first assessment of BCA on SMG development. Although biochanin A is thought to be better tolerated, the presented study presented damaging effect that may exceed that revealed by genistein [14] on submandibular gland.

\section{Material and Methods}

All procedures performed in studies involving animals were in accordance with the ethical standards, and approved by the Ethics Committee of Faculty of Dentistry, Mansoura University, Egypt Materials Biochanin A [BCA] and $17 \beta$ estradiol [E2][[E8875] Sigma Aldrich Co. St Louis, M 0, USA], dimethylsulphoxide [DMSO]; [New Test Co. Egypt, Abbiotec, San Diego].

\section{Study Design}

Pregnant female pathogen free rats were acclimatized in standardized temperature, humidity and phytoestrogen-free diet conditions. To avoid xeno-hormone residues, they 
were housed in individual polypropylene cages. After mating and parturition ninety-six pathogen free female offspring was randomly allocated into four groups, twenty-four each. Group 1 was the control group. In the experimental groups the offspring was injected subcutaneously at [PND] 1, 5, 14, 21, 30, targeting developmental stages, with $500 \mu \mathrm{g} / \mathrm{g}$ body weight of BCA, freshly prepared dissolved in an equal volume of DMSO [1:1] in group 2; 500 $\mathrm{ng} / \mathrm{g}$ body weight of E2 dissolved in sesame oil in group3; while in group4 the corresponding volume of the vehicle was injected [11]. Offspring was euthanized on the $6^{\text {th }}, 15^{\text {th }}, 30^{\text {th }}$ and $60^{\text {th }}$ postnatal days [PND] [six for each time of euthanization]. The submandibular salivary gland pair were surgically removed and separated from sublingual gland, then processed for ultra-structural examination [15].

\section{Ultrastructural examination $[16,17]$}

The procedures were done in Electron Microscopy Unit, Agriculture faculty, Mansoura University.

A. The $1 \mathrm{~mm}$ blocks were fixed primarily in glutaraldehyde $4 \%$ for 2 hours, then in osmic acid solution [1\%] as a secondary fixation for one to two hours, washed in phosphate buffer after each fixation, dehydrated by series of ethanol alcohol, followed by $100 \%$ propylene oxide and then embedded in Epon 812.

B. Semi thin section $[1 \mu \mathrm{m}]$ were stained with toluidine blue, and then examined by light microscope to determine the spot of choice to be ultra-cut for electron microscope examination.

C. The ultrathin sections $[50 \mathrm{~nm}]$, cut using the ultra- microtome, were mounted on grids and were double stained with uranyle acetate and lead citrate, then washed with $\mathrm{N}-\mathrm{NaoH}$ and finally with fresh double distilled water and dried before transmission electron microscope examination.

\section{Results and Discussion}

The striated duct of control group showed distinguishing features of tall columnar cells arranged around the lumen, centrally located nuclei and characteristic basal folding. The acini revealed basally located nuclei with well-defined secretory granules that differed between different age groups. The compounds of concern showed changes in cell height of ductal component compared to the control group, wide intercellular spaces mitochondrial lesions, and dilation of double membrane [rough endoplasmic reticulum] were also noted especially in the striated ducts. The nuclear changes were also prominent both in acinar and ductal structures (Figures 1-4). The acinar basement membrane integrity as well as connective tissue component like telocytes was also affected in DMSO group (Figure 5). The striated duct radial pattern of the mitochondria and the basal infoldings was more evident at $15^{\text {th }}$ PND. These results were similar to those of TEM observation in mouse submandibular gland by Pícoli et al. [18]. Several groupings of secretory granules with different diameters and structure that were noted in proaciniat $6^{\text {th }} \& 15^{\text {th }}$ PND were in agreement with Moreira et al. [19] and Watanabe et al. [20]. They observed that the rat immature acini contain secretory cells of several types at different stages of differentiation and/or maturation, whereas the mature acini are composed only of the serous secretory cell.

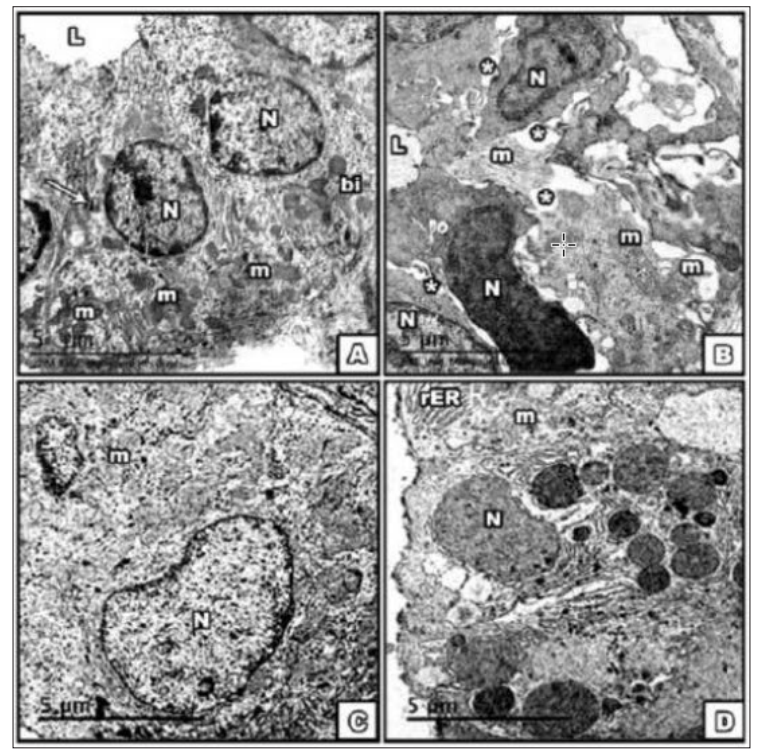

Figure 1: Electron micrograph of SMG at the $15^{\text {th }}$ PND; A. control; B. BCA, C. E2; D. DMSO group, showing part of striated duct with

1-Obvious basal infolding [bi] with several mitochondria radially distributed. The cells are attached to each other by desmosomes $[\rightarrow]$ control group. The basal infoldings was lost in all other groups.

2-In BCA group abnormal size, shape of nuclei.

3-The cells are widely spaced [*] around the lumen [L]. Distortion of mitochondria was evident.

4-E2 gp nuclei of variable size, surrounding the lumen. In DMSO gp striated duct with largely dilated double membrane, ruptured mitochondria. [Scale bar $\rightarrow 5 \mu \mathrm{m}$ ]. 


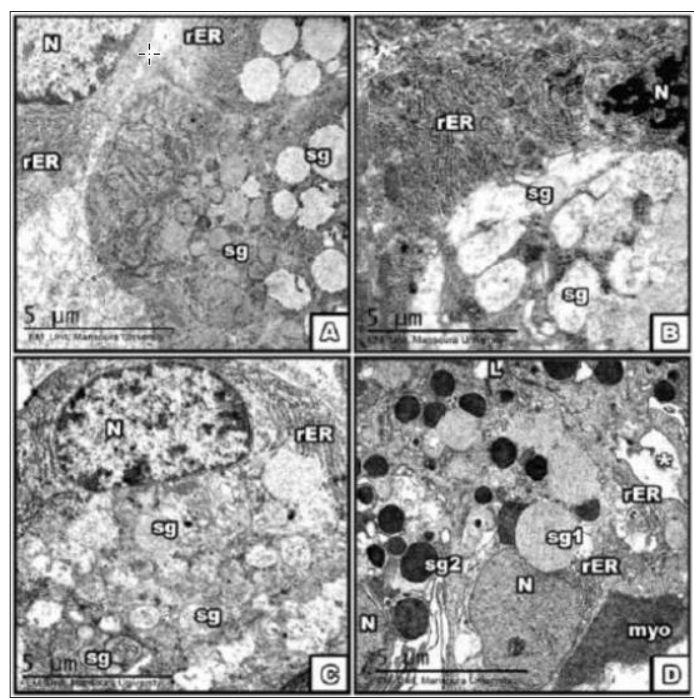

Figure 2: Electron micrograph of SMG at the $15^{\text {th }}$ PNDA. control; B. BCA, C. E2; D. DMSO group showing part of Proacinar cells structure

1-with intact nucleus and electron-lucent and parallel rows of rough Endoplasmic Reticulum in con gp.

2-In BCA cell structure with dissociated and disorganized chromatin in the nucleus, electron lucent secretory granules showing ill preserved wall resulting in formation of lakes of secretion, dilated rough Endoplasmic Reticulum.

3-E2 gp showed multiple secretory granules types, short and dilated rER.

4-DMSO showed two types of secretory granules of different sizes and electron densities; electron lucent [sg1] $\&$ dense [sg2], and wide intercellular spaces [*]. Note myoepithelial cell with enlarged nucleus [myo]. [Scale bar $\rightarrow 5 \mu \mathrm{m}]$.

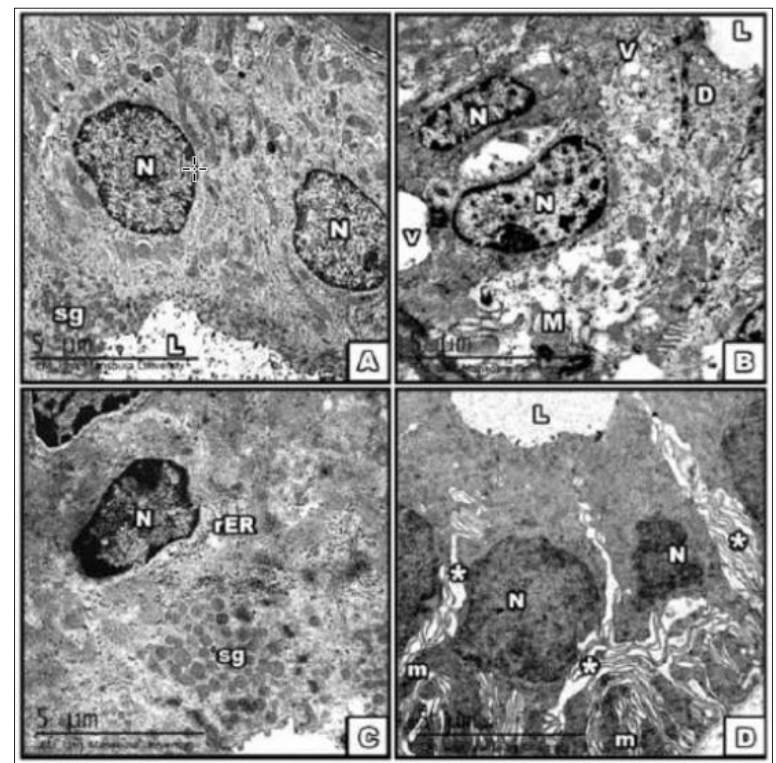

Figure 3: Electron micrograph of SMG at the 30 ${ }^{\text {th }}$ PND A. control; B. BCA, C. E2; D. DMSO group showing part of the striated duct

1-With rounded euchromatic nuclei, radially arranged mitochondria, secretory granules poured into the lumen in cont gp.

2-Heterochromatic dense nuclei, with mitochondrial lesions in BCA gp.

3-The E2 group showed bi-nucleated cell, dilated short $\mathrm{rER}[\rightarrow]$.

4-Different sizes of nuclei and mitochondria in addition to wide intercellular spaces [*] in DMSO. [Scale bar $\rightarrow 5 \mu \mathrm{m}]$. 


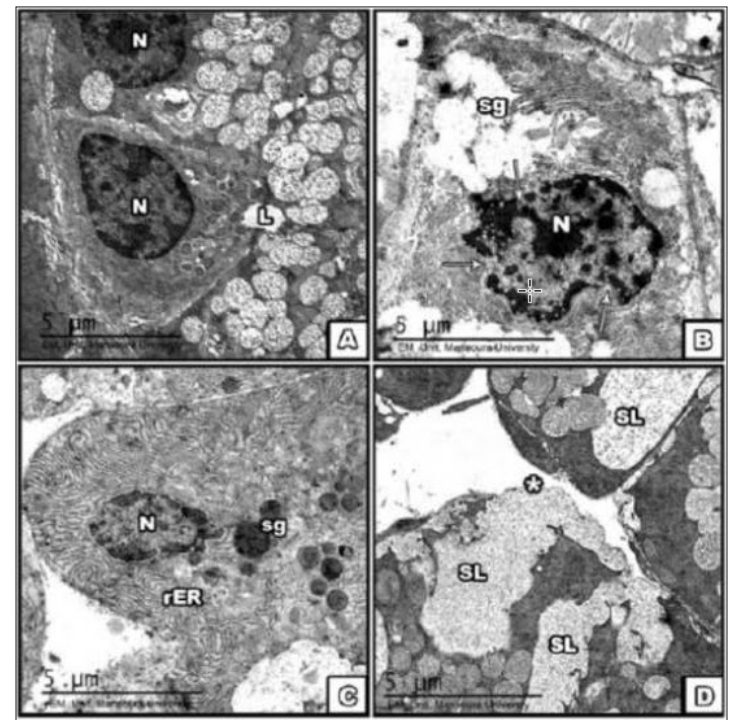

Figure 4: Electron micrograph of SMG at the $30^{\text {th }}$ PND A. control; B. BCA, C. E2; D. DMSO group showing part of the acini with

1-Euchromatic nuclei, 2 type of secretory granules in cells; cont. B-Part of acini with heterochromatic dense nucleus and ruptured nuclear membrane $[\rightarrow]$, multiple sizes and shapes of secretory granules.

2-BCA gp The E2 group showed Part of acinar structure with heterochromatic dense nuclei, dilated rER.

3-Rupture of basal lamina [*] with leakage of fused secretory granules in the DMSO gp. [Scale bar $\rightarrow 5 \mu \mathrm{m}]$.

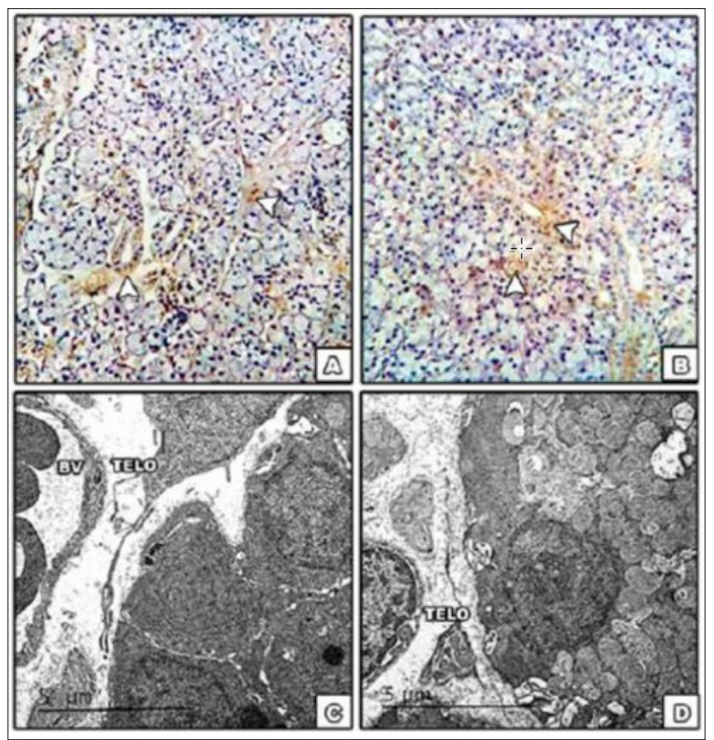

Figure 5: A\& B photomicrograph of SMG of control group showing positive immune histo chemical reaction for both CD 34, vemintin respectively confirming the presence of telocytes around the blood vessels and duct system. [magnification $\mathrm{x}$ 400]. C-Electron micrograph of telocyte [arrow] showing long thin process and podosome in between the blood vessel wall and acinar cell. D. Affected telocyte in DMSO group [arrow] [scale bar 5 $\mathrm{mm}$ ].

In agreement with Przybyło [21] the histo-differentiation presenting more organized intracellular components in the acinar and ductal cells is clearly demonstrated in the TEM images of the $30^{\text {th }} \& 60^{\text {th }}$ PND. Additionally, telocyte cell was observed in ultrathin sections, further confirmed by positive reaction of both vimentin and CD34 staining. Telocyte the recently identified stromal cells consist of small cell body and long processes [telos, i.e. provided with long-distance cell projections]; the thin fibrillar segments are called podomers and the dilated, cistern-like regions are called podoms. Usually found in close contact of blood vessels and nerves, acini and ducts. Telocyte was also affected by DMSO application [2224]. As far as we know this is the first documentation of presence of telocytes in submandibular gland. The presence of telocyte was also observed by Nicolescu et al. [25] in the interlaminar 
and the sub ductal stroma of parotid gland, and in minor salivary glands of primary Sjogren's syndrome by Alunno et al. [26]. The ultrastructure unexpectedly revealed another aspect of BCA and E2 properties reflected on the increased height of the striated duct cells, wide intercellular spaces and bizarre shaped nuclei, not consistent with the normal developmental apoptosis or autophagy. This might be due to the effect of BCA \& E2 on the DNA.

Concomitantly Jefferson et al. [27] revealed that biochanin A and daidzein [isoflavone] affect hormonal endpoints such as increasing uterine gland number and cell height but without increasing uterine weight. In the present study, the secretory granules were of different size and shape and rough endoplasmic reticulum was dilated suggesting that BCA might have modulated the secretory function of the gland. The precise mechanism is not known. Both acinar and ductal component showed changes in nuclei and dilation of rER. In the $30^{\text {th }} \& 60^{\text {th }}$ PND, the BCA, E2 and DMSO groups, showed altered nuclei and cell organelles in electron microscopy results. These results similar to that of De Rijk et al. [28]. who revealed absence of rows of mitochondria and [pseudo]luminal structures formed by variably sized cell, as result of steroid application for long period. Although dilated rough endoplasmic reticulum is associated with reversible cell injury [29], the observed dilatation of RER cisternae in the experimental groups of the current study was a sign of cell injury rather than a sign of increased secretory activity. Vacuolation may be explained as dilated RER cisternae or swollen mitochondria with destructed cristae. Vacuolation may be due to functional loss and disturbed structural integrity of their membranes in the absence of nuclear fragmentation [30] or represents DNA changes in the cell [31] The electron examination revealed alteration of the chromatin condensation either by loss in the peripheral arrangement in some areas or coarse, asymmetric aggregation of densely packed heterochromatin seen in BCA, [sometimes with rupture of nuclear membrane] and E2 groups. The alteration of chromatin spatial arrangement is proposed to alter the macromolecules diffusion inside the nucleoplasm and therefore alters the chromatin's accessibility to transcription factors. Unfortunately, such structural chromatin alterations represent the microscopic characters of pre-neoplastic cell nuclei that probably drive the changes in gene expression during neoplastic transformation $[32,33]$. The distortion observed in DMSO group agrees with Yuan et al. [34] observations. They revealed caspase-3 activation, decreased cell viability, mitochondrial distortion and membrane potential impairment in astrocyte cell culture after exposure to DMSO. The ability of DMSO to cause membrane loosening, pore formation and bilayer collapse may be responsible for the structure distortion [35].

\section{Conclusion and Remarks}

Submandibular gland is targeted by endocrinal disruptor. The degree of damage might be dependent on the window of sensitivity and time of exposure. The use of low dose of Biochanin A should be avoided during early stages of development and growth; further investigation is needed for BCA usage with solvent other than DMSO to avoid the toxicity. Biochanin A affected the gland component not only on the morphological structure.

\section{Conflict of Interest}

There is no conflict of interest with any author.

\section{References}

1. Kole L, Giri B, Manna SK (2011) Biochanin-A an isoflavon, showed antiproliferative and anti-inflammatory activities through the inhibition of iNOS expression, p38-MAPK and ATF-2 phosphorylation and blocking NFkB nuclear translocation. Eur J Pharmacol 653(1-3): 8-15.

2. Lin VC, Ding HY, Tsai PC, Wu JY, Lu YH, et al. (2011) In vitro and in vivo melanogenesis inhibition by biochanin A from Trifolium pratense. Biosci Biotechnol Biochem 75: 914-918.

3. Szliszka E, Czuba ZP, Mertas A, Paradysz A, Krol W (2013) The dietary isoflavone biochanin-A sensitizes prostate cancer cells to TRAIL-induced apoptosis. Urol Oncol 31(3): 331-342.

4. Dornstauder E, Jisa E, Unterrieder I, Krenn L, Kubelka W, et al. (2001) Estrogenic activity of two standardized red clover extracts (menoflavon) intended for large scale use in hormone replacement therapy. J Steroid Biochem Mol Biol 78(1): 65-75.

5. Mansoor TA, Ramalho RM, Luo X, Ramalhete C, Rodrigues CM, et al. (2011) Isoflavones as apoptosis inducers in human hepatoma HuH-7 Cells. Phytother Res 25(12): 1819-1824.

6. Moon YJ, Shin BS, An G, Morris ME (2011) Biochanin A inhibits breast cancer tumor growth in a murine xenograft model. Pharm Res 25(9): 2158-2163.

7. Han HJ, Heo JS, Lee YJ (2006) Estradiol-17 beta stimulates proliferation of mouse embryonic stem cells: involvement of MAPKs and CDKs as well as proto-oncogenes. Am J Physiol Cell physiol 290(4): C1067-1075.

8. Öz OK, Zerwekh JE, Fisher C, Graves K, Nanu L, et al. (2000) Bone has a sexually dimorphic response to aromatase deficiency. J Bone Mineral Res 15(3): 507-514

9. Yue W, Wang JP, Hamilton CJ, Demers LM, Santen RJ (1998) In situ aromatization enhances breast tumor estradiol levels and cellular proliferation. Cancer Res 58(5): 927-932.

10. Guidozzi F, Alperstein A, Bagratee JS, Dalmeyer P, Davey M, et al. (2014) South African Menopause Society revised consensus position statement on menopausal hormone therapy. S Afr Med J 104(8): 537-543.

11. Mishra P, Kar A, Kale RK (2009) Influence of pre-pubertal biochanin A exposure on mammary gland differentiation and expression of estrogen receptor- $\alpha$ and apoptotic proteins. Phytother Res 23(7): 972-979.

12. Tsinti M, Kassi E, Korkolopoulou P, Kapsogeorgou E, Moutsatsou P, et al. (2009) Functional estrogen receptors alpha and beta are expressed in normal human salivary gland epithelium and apparently mediate immunomodulatory effects. Eur J Oral Sci 117(5): 498-505.

13. Denny PC, Ball WD, Redman RS (1997) Salivary glands: a paradigm for diversity of gland development, Crit Rev Oral Biol Med 8(1): 51-75.

14. Kouidhi W, Desmetz C, Nahdi A, Bergès R, Cravedi JP, et al. (2012) In utero and lactational exposure to low-dose genistein-vinclozolin mixture affects the development and growth factor mRNA expression of the submandibular salivary gland in immature female rats. Toxicol Pathol 40(4): 593-604.

15. Jonjic S (2001) Surgical removal of mouse salivary glands. Curr Protoc Immunol Chapter 1: Unit 1.

16. King (1992) Principles and techniques of electron microscopy: biological application. J Anat 181(pt2): 385-386.

17. Hayat (200) Principles and techniques of electron microscopy: biological application ( $\left.4^{\text {th }} e d n\right), 2000: 578$.

18. Pícoli LC, Dias FJ, Issa JP, Ogawa K, Ciena A, et al. (2011) Ultrastructure of submandibular salivary glands of mouse: TEM and HRSEM observations. Microsc Res Tech 74(12): 1154-1160. 
19. Moreira JE, Ball WD, Mirels L, Hand AR (1991) Accumulation and localization of two adult acinar cell secretory protein during development of the rat submandibular gland. Am J Anat 191(2): 167-184.

20. Watanabe I, Jin C, Nagata T (1997) Field emission SEM, conventional TEM and HVTEM study of submandibular gland in prenatal and postnatal aging mouse. Histol Histopathol12(2): 447-457.

21. Przybyło M, Lityńska A, Hoja Łukowicz D, Kremser E (2004) Rat submandibular gland during the maturation process: changes in enzyme activities, protein and lectin-binding profiles. Physiol Res 53(3): 317-326.

22. Popescu LM (2011) The Tandem: telocytes-stem cells. Int J Biol Biomed Eng 5(2): 83-92.

23. Flores DL, Gutiérrez R, García MP, Sáez FJ, Flores DL, et al. (2014) CD34 stromal cells/fibroblasts/fibrocytes/ telocytes as a tissue reserve and a principal source of mesenchymal cells. Location, morphology, function and role in pathology. Histol Histopathol 29(7): 831-870.

24. Cretoiu SM, Popescu LM (2014) Telocytes revisited. Biomol Concepts 5(5): 353-369.

25. Nicolescu MI, Bucur A, Dinca O, Rusu MC, Popescu ML (2012) Telocytes in parotid glands. Anat Rec 295(3): 378-385.

26. Alunno A, Ibba Manneschi L, Bistoni O, Rosa I, Caterbi S, et al. (2015) Telocytes in minor salivary glands of primary Sjogren's syndrome: association with the extent of inflammation and ectopic lymphoid neogenesis. J Cell Mol Med 19(7): 1689-1696.

27. Jefferson WN, Padilla Banks E, Clark G, Newbold RR (2002) Assessing estrogenic activity of phytochemicals using transcription al activation and immature mouse uterotrophic responses. J Chromatogr B Analyt Technol Biomed Life Sci 777(1-2): 1179-1189.
28. De Rijk EP, Ravesloot WT, Hafmans TG, van Esch E (2003) Multifocal ductal cell hyperplasia in the submandibular salivary glands of Wistar rats chronically treated with a novel steroidal compound. Toxicol Pathol 31(1): 1-9.

29. Myers RK, McGavin MD (2007) Cellular and tissue responses to injury. In: Pathologic Basis of Veterinary Disease, (4 $4^{\text {th }}$ edn), McGavin MD, Zachary JF (Eds.), Mosby, St Louis, Missouri, USA, pp. 14-62.

30. Hargis AM, Ginn PE (2007) The integument. In: Pathologic Basis of Veterinary Disease, ( $4^{\text {th }}$ edn), McGavin MD, Zachary JF, Eds.), Mosby, St Louis, Missouri, USA, pp.1107-1261.

31. Amano O, Kudo Y, Shimada M, Wakayama T, Yamamoto M, et al. (2001) Transient occurrence of $27 \mathrm{kDa}$ heat-shock protein in the terminal tubule cells during postnatal development of the rat submandibular gland. Anat Rec 264(4): 358-366.

32. Cherkezyan L, Stypula Cyrus Y, Subramanian H, White C, Dela Cruz M, et al. (2014) Nanoscale changes in chromatin organization represent the initial steps of tumorigenesis: a transmission electron microscopy study. BMC Cancer 14: 189.

33. Misteli T (2010) Higher-order genome organization in human disease. Cold Spring Harb Perspect Biol 2(8): a000794.

34. Yuan C, Gao J, Guo J, Bai L, Marshall C, et al. (2014) Dimethyl sulfoxide damages mitochondrial integrity and membrane potential in cultured astrocytes. PLoS One 9(9): e107447.

35. de Ménorval MA, Mir LM, Fernández ML, Reigad R (2012) Effects of dimethyl sulfoxide in cholesterol-containing lipid membranes: a comparative study of experiments in silico and with cells. PLoS One 7(7): e41733. 